\title{
Correction to "A Scale of Agonism and Allosteric Modulation for Assessment of Selectivity, Bias, and Receptor Mutation"
}

The above article (Kenakin T, Mol Pharmacol. 2017 October; 92(4): 414-424; DOI: https:// doi.org/10.1124/mol.117.108787), contained a Figure without a caption. It should be listed as below.

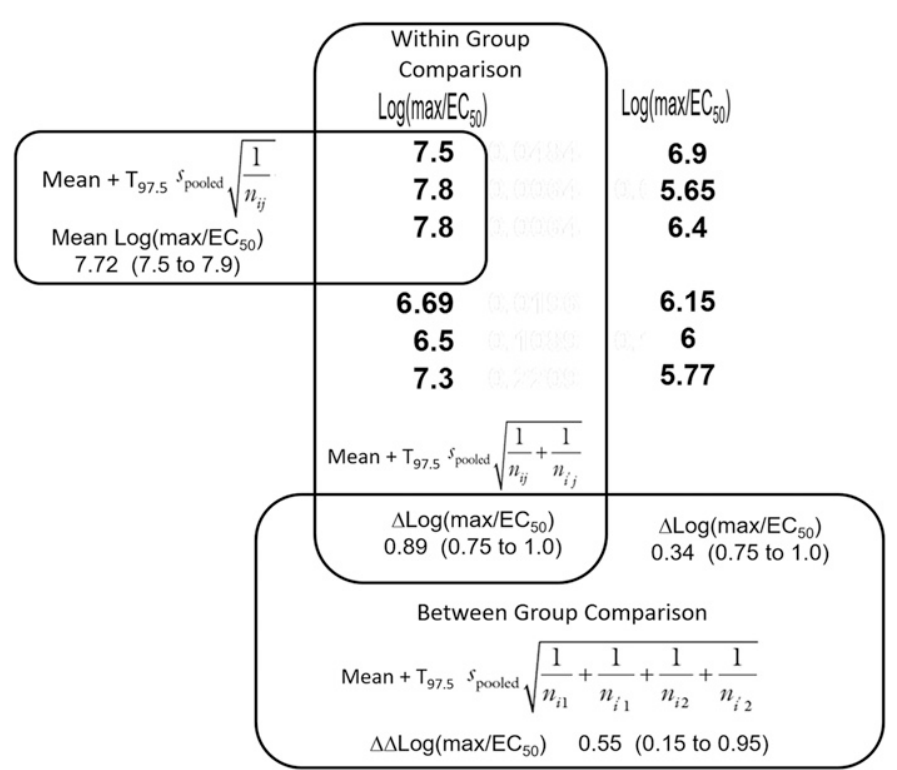

Fig. 11. The application of equations (24) through (29).

All versions of the article are corrected with the issuance of this erratum.

The compositor regrets this error and any inconvenience it may have caused. 